\title{
Simulation of the carbides precipitation mechanism in 34CrMo4 and 42CrMo4 steels
}

\author{
Miroslav Kvicala, Michaela Stamborska* \\ Department of Non-ferrous Metals, Rafination and Recyclation, VŠB - Technical University of Ostrava, 17. listopadu 15/2172, 708 33 \\ Ostrava - Poruba, Czech Republic
}

\section{Email address:}

miroslav.kvicala@vsb.cz (M. Kvicala),stamborska.michaela@gmail.com (M. Stamborska)

\section{To cite this article:}

Miroslav Kvicala, Michaela Stamborska. Simulation of the Carbides Precipitation Mechanism in 34CrMo4 and 42CrMo4 Steels. International Journal of Materials Science and Applications. Vol. 3, No. 6, 2014, pp. 309-313. doi: 10.11648/j.ijmsa.20140306.15

\begin{abstract}
The low-alloyed Cr-Mo steels (25CrMo4, 34CrMo4 and 42CrMo4) are used for production of important technical equipment parts in the petrochemical industry, for transportation of the gaseous hydrocarbons, concentrated acids, and lyes. They are also used for rolling of seamless tubes, in the production of pressure bottles, steel bolts, etc. Steel grades $25 \mathrm{CrMo} 4$ and $34 \mathrm{CrMo} 4$ represents materials with improved mechanical properties, mainly due to vanadium microalloying. Unfortunately, vanadium microalloyed steels are very sensitive to cracks occurrence after continuous casting and/or heating before hot rolling. This paper deals with vanadium rich precipitates $M C, M_{3} C_{2}$ and $M_{7} C_{3}$ formation during continuous casting process. It was verified that vanadium microalloyed steel $34 \mathrm{CrMo} 4$ exhibited different carbides formation mechanism and contained significantly higher rate of vanadium in $\mathrm{M}_{\mathrm{x}} \mathrm{C}_{\mathrm{y}}$ carbides than steel grade $42 \mathrm{CrMo} 4$ using experimental data and ThermoCalc software. Understanding of the vanadium precipitation kinetics is necessary for manufacturing process optimization and internal defects limitation.
\end{abstract}

Keywords: Cracks, Precipitation, Vanadium, 34CrMo4, 42CrMo4

\section{Introduction}

Vanadium microalloyed steel grades $25 \mathrm{CrMo} 4$ and $34 \mathrm{CrMo} 4$ are commonly produced under the same conditions as $42 \mathrm{CrMo} 4$ steel. The only relevant difference among these steel grades is vanadium content. Based on the manufacturing experience it was discovered that $24 \mathrm{CrMo} 4$ and $34 \mathrm{CrMo} 4$ steels are significantly more sensitive to the cracks that occurred after continuous casting and/or heating in the soaking pit [1-5]. Critical points of the manufacturing process were already identified. Among them there is the enormous overheating temperature in the tundish [6], the low steel casting speed, the occurrence of central segregations [7], the non-uniform intensity of secondary cooling during casting, the insufficient reduction of central parts of the rolled stock [1], the unsuitable interval of the forming temperatures [8], and the non-uniform friction between the rolled stock and the roll [8]. Statistical analysis, artificial neural networks, finite elements methods, microchemical analysis and mictrostructure study led to successful reduction of the internal cracks occurrence [9-11].

Precipitation of the vanadium is carried out by creation of
$\mathrm{VN}, \mathrm{V}(\mathrm{C}, \mathrm{N})$ and precipitation of $\mathrm{VC}$ occurs only after exhaustion of nitrogen stocks in steel. In reality, pure vanadium nitrides can be observed rarely. The most frequently, carbonitrides complexes can be observed, $\mathrm{C} / \mathrm{N}$ rate is determined by the availability of nitrogen. In the initial stage of precipitation, when amount of the nitrogen is high enough the carbon content in $\mathrm{V}(\mathrm{C}, \mathrm{N})$ represent about $5 \%$ of the carbonitride weight and with decreasing availability of nitrogen, this rate is growing [12]. When the temperature $1193 \mathrm{~K}$ is achieved there is no longer any nitrogen available. Below this temperature, vanadium precipitates only in the form of $\mathrm{VxCy}$. Vanadium precipitation is completed at about $973 \mathrm{~K}[13]$.

In terms of the $\mathrm{VC}, \mathrm{VN}$ and $\mathrm{V}(\mathrm{C}, \mathrm{N})$ precipitation mechanism it is possible to state that the precipitation occurs in the stable austenite through heterogeneous nucleation of the $\mathrm{VC}, \mathrm{VN}$ and $\mathrm{V}(\mathrm{C}, \mathrm{N})$ on the dislocations, austenite grain boundaries and the MnS particles [2,3]. In many cases it can arise even complex multiphase inclusions, it is possible to observe multiphase inclusions such as $\mathrm{MnS},(\mathrm{Ti}, \mathrm{V})(\mathrm{C}, \mathrm{N})$ and AlN [14]. The negative effect of precipitation of carbides, nitrides and carbonitrides of vanadium is realized during the 
continuous casting, if the proper casting conditions are not guaranteed. Continuously cast blooms straightening within the critical temperature range $(1073-1273 \mathrm{~K})$ on the radial casting machines creates unfavourable stress-strain conditions that contributes to the initiation and propagation of the internal cracks [1-3]. Typical internal defect present in $34 \mathrm{CrMo} 4$ steel after hot-rolling is shown on Fig.1.

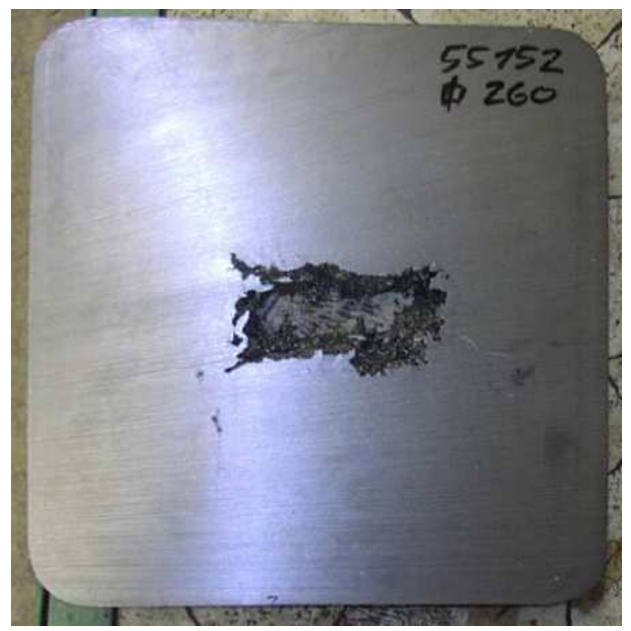

Figure 1. Transverse cut of the hot-rolled billet made from 34CrMo4 steel with internal defect.

This paper deals with ThermoCalc calculations that allow qualitative and quantitative prediction of the newly created precipitates.

\section{Materials and Methods}

Two low-alloyed Cr-Mo steel grades, namely 34CrMo4 and
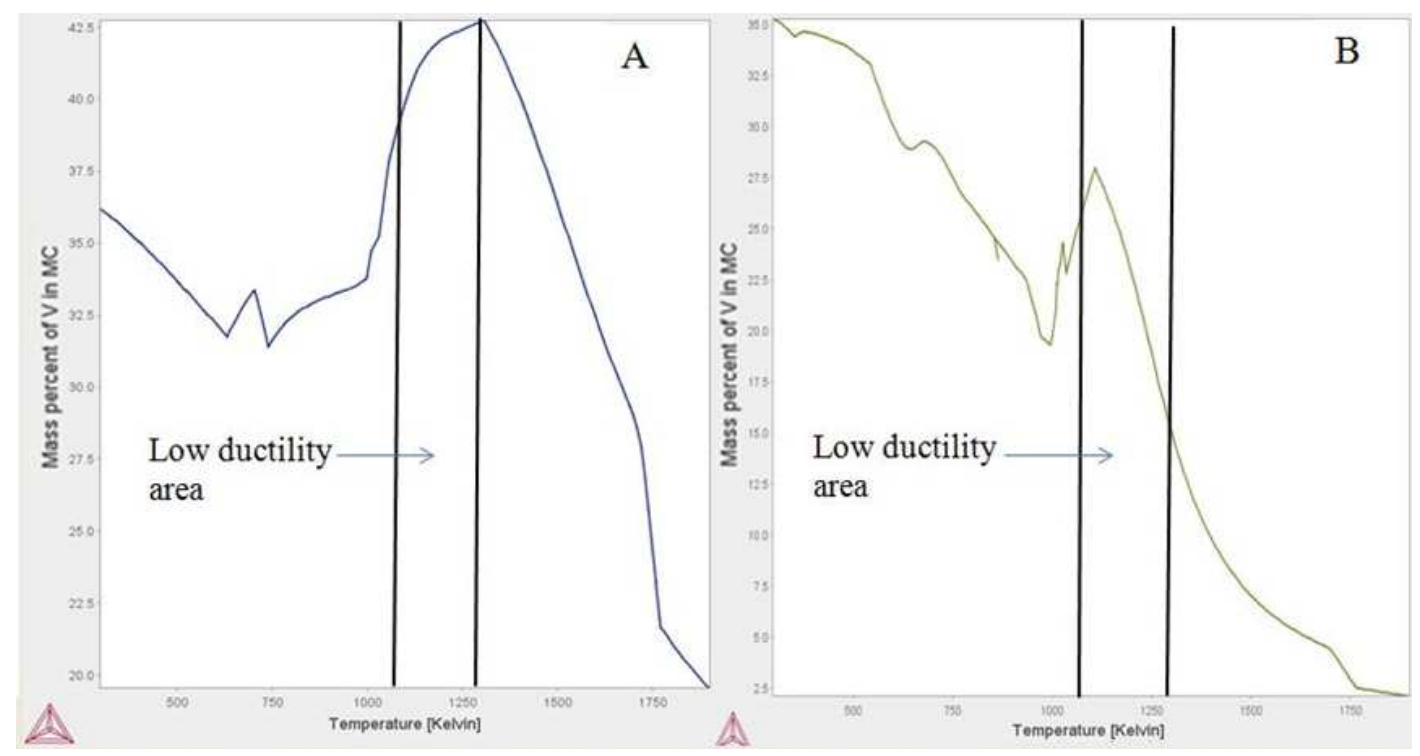

Figure 2. Mass percent of the vanadium that precipitated in form of the VC, $A-34 C r M o 4, B-42 C r M o 4$. precipitation during the continuously cast blooms straightening is very significantly reduced. In case of the $34 \mathrm{CrMo} 4$ steel vanadium/nitrogen rate is high enough for
Because of this fact negative effects of the vanadium
$42 \mathrm{CrMo} 4$, were chosen for calculation of the precipitation kinetics parameters. Typical chemical composition of the studied steels is shown in Tab.1.

Table 1. Chemical composition of low-alloyed Cr-Mo steels (wt. \%).

\begin{tabular}{lllllllllll}
\hline Steel & $\mathbf{C}$ & $\mathbf{M n}$ & $\mathbf{S i}$ & $\mathbf{P}$ & $\mathbf{S}$ & $\mathbf{N}$ & $\mathbf{C r}$ & $\mathbf{N i}$ & $\mathbf{M o}$ & $\mathbf{V}$ \\
\hline 34CrMo4 & 0,34 & 0,74 & 0,25 & 0,015 & 0,005 & 0,008 & 1,17 & 0,25 & 0,20 & 0,088 \\
42CrMo4 & 0,42 & 0,74 & 0,25 & 0,015 & 0,005 & 0,008 & 1,18 & 0,25 & 0,20 & 0,005 \\
\hline
\end{tabular}

ThermoCalc 3.1 software and it's material databases were used for calculations of the vanadium mass percentage content in $\mathrm{M}_{\mathrm{x}} \mathrm{C}_{\mathrm{y}}$ precipitates. The studied variables were precipitation profile with respect to the low ductility zone and vanadium content $\mathrm{M}_{\mathrm{x}} \mathrm{C}_{\mathrm{y}}$ precipitates. The samples taken from both steel grades (transverse cut of the continuously cast bloom) were cooled down in liquid nitrogen $(77 \mathrm{~K})$ and broken by Charpy impact tester. Fracture surface of analyzed steels were studied using SEM TESCAN Mira. Extraction carbon replicas were prepared by etching $\left(10 \% \mathrm{HNO}_{3}\right.$ in alcohol, $298 \mathrm{~K}$, voltage 10 V). Thereafter, the replicas were studied by TEM JEM $200 \mathrm{CX}$ and minority phases were identified by EDX X-rays microanalysis.

\section{Results and Discussion}

Due to the absence of the titanium in above discussed steel grades it can be expected that most of the vanadium atoms precipitates in form of the $\mathrm{VN}$ in case of both $34 \mathrm{CrMo} 4$ and $42 \mathrm{CrMo} 4$ steels. This process occurs during continuous casting predominantly at higher temperatures, than are typical for low ductility zone. precipitation of the carbides and carbonitrides. Most of the "free" vanadium which is available in the austenite when the nitrogen resources are exhausted, precipitates in form of the $\mathrm{VC}$ and/or relevant multiphase carbides and carbonitrides, 
see Fig.2A,B.

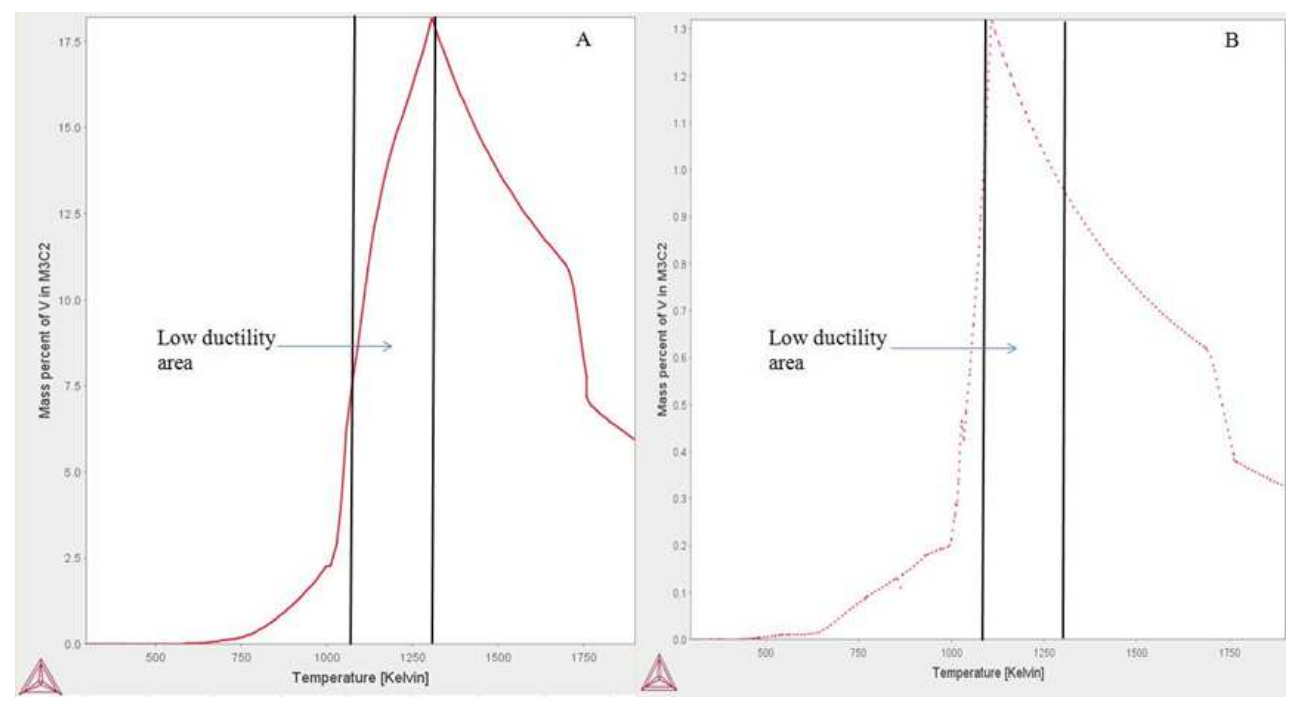

Figure 3. Mass percent of the vanadium that precipitated in form of the $V_{3} C_{2}, A-34 C r M o 4, B-42 C r M o 4$.

Meanwhile, vanadium content in $\mathrm{VC}$ precipitates is quite high even in $42 \mathrm{CrMo} 4$ steel, in case of the $\mathrm{V}_{3} \mathrm{C}_{2}$ and relevant multiphase carbides and carbonitrides, 34CrMo4 steel contents almost 14 times higher amount of vanadium in form of $\mathrm{V}_{3} \mathrm{C}_{2}$ precipitates compared to the $42 \mathrm{CrMo} 4$ steel, see Fig.3.

Formation of the $\mathrm{V}_{7} \mathrm{C}_{3}$ carbides exhibited similar trend that was observed in case of $\mathrm{V}_{3} \mathrm{C}_{2} .34 \mathrm{CrMo} 4$ steel contains still sufficient amount of vanadium for precipitation of $\mathrm{V}_{7} \mathrm{C}_{3}$ carbides, however, vanadium content in $42 \mathrm{CrMo} 4$ steel is almost exhausted. Although, even in $34 \mathrm{CrMo} 4$ steel vanadium content decreases with decreasing thermodynamical stability of the precipitates, see Fig. 4.

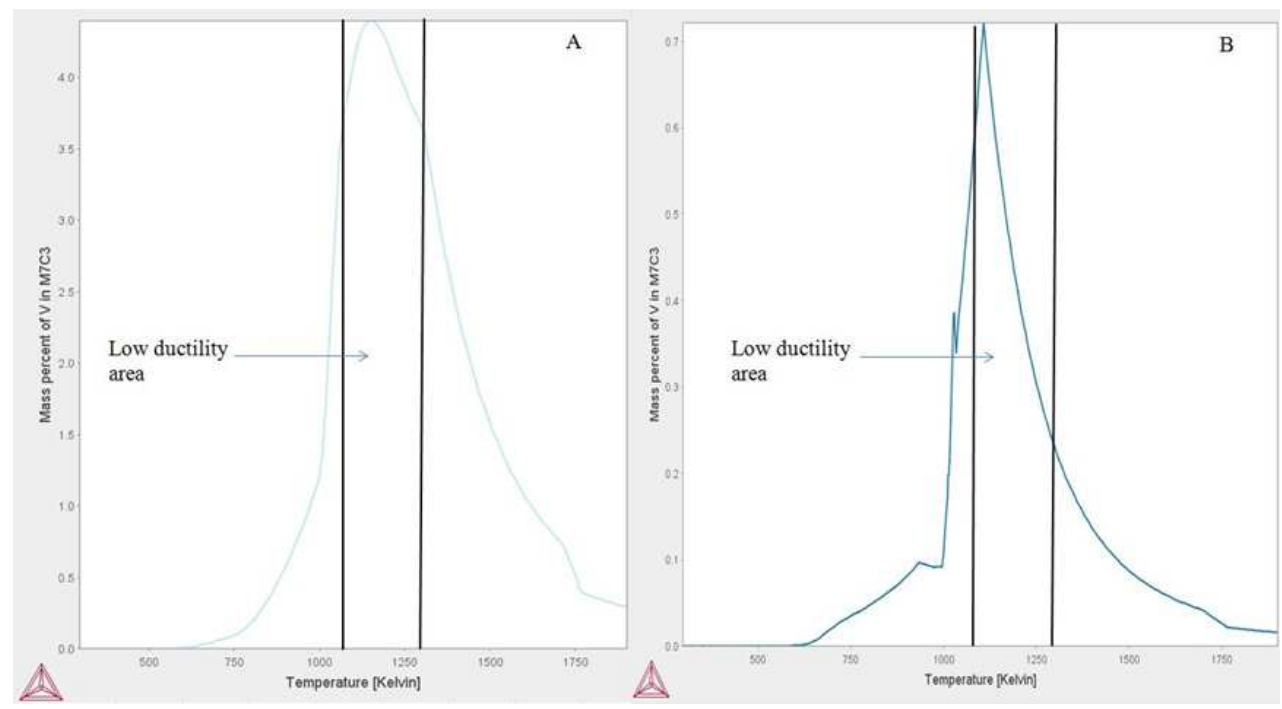

Figure 4. Mass percent of the vanadium that precipitated in form of the $\mathrm{V}_{7} \mathrm{C}_{3}, \mathrm{~A}-34 \mathrm{CrMo} 4 \mathrm{~B}-42 \mathrm{CrMo} 4$.

Due to the fact that $34 \mathrm{CrMo} 4$ steel is very sensitive to the internal defects occurrence, prediction possibilities of the ThermoCalc software were compared with the results of TEM analysis of the extraction replicas. ThermoCalc claimed that chrome will be present in form of $\mathrm{M}_{23} \mathrm{C}_{6}$.
This result was fully confirmed by extraction replicas analysis. Chrome was present especially in form of $\mathrm{Cr}_{23} \mathrm{C}_{6}$ precipitates both for specimen taken form bloom's surface and internal part, see Fig. 5. 

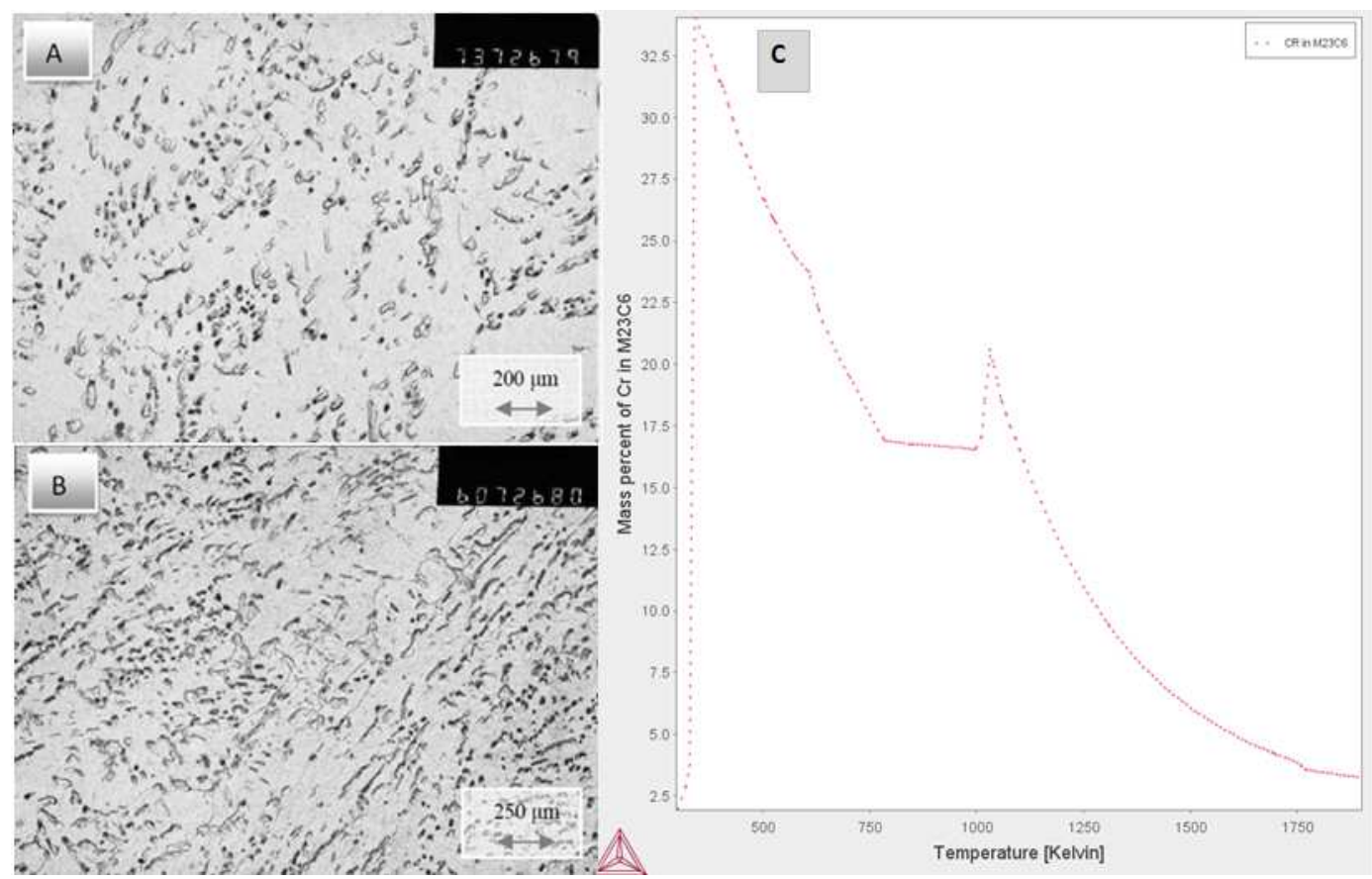

Figure 5. TEM images of the $34 \mathrm{CrMo} 4$ steel represent precipitates distribution in the internal crack surrounding. A-bloom surface, $B$ - bloom center, mass percent of the chrome that precipitated in form of the $\mathrm{Cr}_{23} \mathrm{C}_{6}$.

Although, ThermoCalc represents useful tool for qualitative and quantitative phase analysis, it does not allow to take into account influence of steel heterogeneity. For more accurate results it is beneficial to realize at least two microchemical analysis for internal and surface parts of the studied material.

\section{Conclusions}

Calculation of the precipitation kinetics represents perspective trend in expansion of the methods that can be used in material research. ThermoCalc simulations were used for prediction of the precipitation characteristics of the $34 \mathrm{CrMo} 4$ and $42 \mathrm{CrMo} 4$ steels. In this paper it was demonstrated that even small difference in steels chemical composition can be responsible for the serious manufacturing problems such as internal cracks occurrence in low-alloyed Cr-Mo steels. ThermoCalc calculations were mainly focused on vanadium carbides that are responsible for internal cracks initiation and propagation if favourable production conditions cannot be guaranteed. ThermoCalc calculations can be used not only for description and explanation of precipitation process but also allow to simulate possible steel's chemical composition modifications without necessity of the material production and structural analysis.

\section{Acknowledgements}

This paper has been elaborated in the framework of the project Opportunity for young researchers, reg. no. CZ.1.07/ 2.3.00/30.0016, supported by Operational Programme Education for Competitiveness and cofinanced by the European Social Fund and the state budget of the Czech Republic.
This paper was created in the Project No. LO1203 "Regional Materials Science and Technology Centre Feasibility Program" funded by Ministry of Education, Youth and Sports of the Czech Republic.

\section{References}

[1] M. Kvicala, A. Hendrych, O. Zivotsky, P. Jandacka, "The influence of $\mathrm{Cr}, \mathrm{Mn}$ and Mo elements on cracks occurrence in low alloyed Cr-Mo steels," Acta Metallurgica Slovaca, 16 (2), pp. 122-126, 2010.

[2] A. Hendrych, M. Kvicala, V. Matolin, O. Zivotsky, P. Jandacka, "The influence of vanadium microalloying on voids occurence in low alloyed Cr-Mo steels after continuous casting," International Journal of Fracture, 168 (2), (2011) 259-266.

[3] M. Kvicala, K. Frydrysek, A. Hendrych, "Stress-strain behaviour simulation of vanadium microalloyed steel with the internal defects during two different heating strategies," International Journal of Fracture, 181 (1), pp. 139-146, 2013.

[4] Z. Jancikova, O. Zimny, M. Kvicala, P. Kostial, R. Meca, "Prediction of internal defects in rolled products from $\mathrm{Cr}-\mathrm{Mo}$ steels using artificial intelligence methods," 22nd International Conference on Metallurgy and Materials (METAL), pp. 1932 1937, 2013.

[5] G. L. Dunlop, C.,J. Carlsson, G. Frimodig, "Precipitation of $\mathrm{VC}$ in ferrite and pearlite during direct transformation of a medium carbon microalloyed steel," Metallurgical and Materials Transactions A 9, pp. 261-266, 1978.

[6] M. Kvicala, K. Frydrysek, A. Hendrych, "Influence of different heating strategies on stress strain behaviour of continuously cast bloom with with and without internal defect," 22nd International Conference on Metallurgy and Materials (METAL), pp. 554 - 559, 2013. 
[7] T. N. Baker, "Processes, microstructure and properties of vanadium microalloyed steels," Materials Science and Technology 25, pp. 1083-1107, 2009.

[8] M. Kvicala, M. Klimek, I. Schindler, "Study of Technological Formability of Low-alloyed Steel 25CrMo4," Hutnické listy 6, pp. 13-15, 2009.

[9] B. Mintz, R. Abushosha, "Influence of Vanadium on Hot Ductility of steel," Ironmaking and Steelmaking 20 (6), pp. $445-452,1993$.

[10] M. Stamborska, M. Losertova, V. Mares, L. Horsak, "Stress analysis in cylindrical specimens made from 34CrMo4 using DIC," Acta Metallurgica Slovaca 20 (2), pp. 229 - 235, 2014.

[11] M. Kvicala, A. Hendrych, K. Frydrysek, "Continously cast bloom with internal defect - FEM model optimization," Acta Metallurgica Slovaca 20 (1), pp. 5-10, 2014.
[12] Y. Li, "Dispersion strengthening in vanadium microalloyed steels processed by simulated thin slab casting and direct charging Part 1: Processing parameters, mechanical properties and microstructure," Materials Science and Technology 23, (5), pp. 509-518, 2007.

[13] C. Scott, F. Perrard, P. Barges, "Microalloying with Vanadium for Improved Cold Rolled TRIP Steels," International Seminar 2005 on Application Technologies of Vanadium in Flat Rolled Steels 4, pp. 13 - 26, 2005.

[14] M.J. Balart, C.L. Davis, M. Strangwood, "Fracture behaviour in medium carbon Ti-V-N and microalloyed ferritic - pearlitic and bainitic forming steels with enhanced machinability," Materials Science and Engineering A 28 (1), pp. 48 - 57, 2002. 